\title{
Studies on Liver Function in Alloxan Diabetes
}

\author{
By \\ Sigemiti Tuda \\ (津田重 通) \\ (From the Mdical Clinic of Prof. T. Kurokawa, \\ Tohoku University, Sendai) \\ (Received for publication, December 15, 1951)
}

It is an old recognized fact that diabetes mellitus has a close bearing on the metabolic function of the liver, often causing its disturbance. Recently minute investigations have been done on latent disturbance by various liver function tests, but the results arrived at by the researchers are not always in agreement. Reports in which influences of dietary treatment on liver function are pursued are very few.

On the other hand, many researchers acknowledged the pathohistological changes of liver in case of alloxan diabetes, but as shall be stated later, we have had no report giving satisfactory observations on liver function.

I made alloxan diabetes induced in rabbits and tried to inquire into the functioning of liver in its natural process and at the same time the effect upon the liver function of the standard diet, which had been given to some of the stricken rabbits.

\section{EXPERIMENTAL \\ Method}

Animals employed were adult male rabbits weighing $1.8-2.7 \mathrm{~kg}$. when the experiment was begun. These animals were fed as much as they desired all through the period of experiment except for a short time of "standard diet." In good health they ate $130-150 \mathrm{~g}$. of tofukara (bean-curd husk) and 80-100 g. of vegetables or greens per kg. of body weight per day, but 1.5-2.5 times as much when they suffered from diabetes. By the way the "standard diet" consists of $120 \mathrm{~g}$. of tofukara and $60 \mathrm{~g}$. of vegetables or greens per $\mathrm{kg}$. per day.

Tests applied for liver function were sodium santonate test ( $S$ test) and azorubin $\mathrm{S}$ test (A-S test), the former being used as detoxicating test and the latter as excretory function test.

$\mathrm{S}$ test was applied after Takasugi-Miyamoto's method ${ }^{1)}$; only to one same animal the same dosage of santonate as that administered in 
the first test was always given regardless of the loss of its weight.

In A-S test always $2 \mathrm{cc}$. of $1 \%$ A-S solution was intravenously injected. The amount of this dye excreted in the urine after an hour was determined by using Dubosq's colorimeter and the percentage of the amount excreted to that injected was obtained.

After more than a week's acclimatization liver function tests were put to each animal to know its normal value. I obtained the average value of more than three successive tests where almost equal readings were got; then alloxan was administered.

To most of the animals a large dosage (190-200 mg. per $\mathrm{kg}$. of body weight) and to a part a small dosage (100 mg. per $\mathrm{kg}$.) of alloxan were intravenously injected each at a single time.

Blood sugar was determined through Fujita-Iwatake's method ${ }^{21}$ in the morning fasting time of the subject.

For renal injury after injection examination was made by albuminuria and phenolsulfonphthalein test (PSP test) and when there was found any injury liver function tests were not carried out.

\section{Results}

1) Appearance of alloxan diabetes and their classification

Among the 32 rabbits to which alloxan had been administered, diabetes was observed to have appeared in 26 cases out of 28 with a large dose injected and 2 cases out of 4 given a small amount, the 4 others not responding.

It was 21 among these 32 that were with satisfaction employed for my observation of liver function. They are classified under the following 4 types for the convenience of consideration.

Type I (Cases 1-4): To this type belong those animals that suffered from serious diabetes, rapidly grew weaken, and died in the early stage of the disease. In all the cases alloxan was administered in large amount.

Type II (Cases 5-12): In these cases permanent diabetes was induced. All the rabbits of this type were given a large dose except Case 11 into which a small dose was injected.

Type III (Cases 13-17): Under this type those animals fall which presented transitory diabetes. Glycosuria, which had been found in all the cases of this type, disappeared within 3 weeks. In 4 cases a large, and in 1 case a small quantity of alloxan had been administered.

Type IV (Cases 18-21): This type consists of 4 cases in which alloxan found no response. Two were given a large amount and the other two a small amount.

2) Duration of renal injury after alloxan administration 
In the group injected with small amount renal injury was detected in netither of the 4 cases including Case 11 of Type II, but in the other with large amount 13 cases out of $17(76.5 \%)$, the 2 cases of Type IV included, gave albuminuria. Albuminuria was most remarkably found about 24 hours after alloxan administration, occasionally accompanied by macroscopic hematuria; then speedily better on towards recovery, and disappeared in 2-10 days (in most cases 5 days).

According to PSP test the duration of excretory dysfunction of the kidney was in all cases corresponding to that of presence of albuminuria; only three cases required 1-3 days more to be recovered after the disappearance of albuminuria.

To say in addition, incidental injury in the kidney seemed to have hardly anything to do with the diabetes or its severity.

3) Liver function

\section{a) $S$ test}

Type I. In all cases the output of the dye (santogenin) decreased remarkably (i.e. lower than $16 \%$ of normal value) on the occurrence of diabetes, decreasing more and more towards 0 as time went and in the 3rd or the 4th week after injection the diabetic animals died.

Type II. As shown in Table I and Fig. 1, the curves of output fell sharply simultaneously with the appearance of diabetes in all cases except Case 12 which escaped satisfactory observation in its early stage, arriving at their lowest values (8.3-31.1\% of normal value) in the 1 st or 2 nd week. The curves thereafter rose again and culminated about 4 weeks after the administration. The readings at their uttermost points, however, are considerably lower than normal values except in Case 6.

In chronic diabetes extending beyond the 5 th week, the curves, in so far as some special controling treatment was not given, ran, generally in the sphere lower than normal level, almost in response to the severity of diabetes. In other words, the output increased towards normal level as diabetes improved (Cases 7, 8, 10 and 12), decreased off the level as it deteriorated (Cases 5, 6, 9 and 10), and further decreased towards 0 when the disease was critically serious (Cases 5, 6 and 9).

Type III. In all cases the output decreases and increases in a curve similar to that described by Type II. But in this type the lowest value is generally higher (18.3-61.1\% of normal value) than in Type II, the curve not stopping rising about the 4 th week till it reaches the normal level before the diabetes has been recovered.

Type IV. The curve of output of this type resembles that of Type III, but the lowest value reached in the 1 st or 2 nd week was generally far higher (32.9-77.1\% of normal value) than that in Type III and re- 
covery since then was expedite. Normal value was reached in all cases in the 2nd to 4 th week.

TABLE I

Liver Function in Alloxan Diabetes

\begin{tabular}{|c|c|c|c|c|c|c|c|c|c|c|c|c|}
\hline \multirow{2}{*}{ 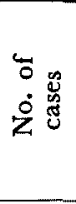 } & \multirow{2}{*}{$\stackrel{0}{2}$} & \multirow{2}{*}{ Test* } & \multirow{2}{*}{ 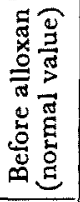 } & \multicolumn{9}{|c|}{ After alloxan (weeks) } \\
\hline & & & & 1 & 2 & 3 & 4 & 5 & 7 & 10 & 15 & 20 \\
\hline 5 & II & $\begin{array}{c}\text { B S } \\
A-S \\
S\end{array}$ & $\begin{array}{c}103 \\
26.1 \\
24\end{array}$ & $\begin{array}{l}460 \downarrow \\
\times\end{array}$ & $\begin{array}{c}352 \\
28.3 \\
\times \quad 4\end{array}$ & $\begin{array}{c}292 \\
28.2 \\
4\end{array}$ & $\begin{array}{c}295 \downarrow \\
26.5 \\
16\end{array}$ & $\begin{array}{c}270 \downarrow \\
26.0 \\
20\end{array}$ & $\begin{array}{c}320 \\
25.9 \\
11\end{array}$ & $\begin{array}{c}418 \\
25.6 \\
15\end{array}$ & $\begin{array}{c}425 \\
29.1 \\
11\end{array}$ & $\begin{array}{c}186 \dagger \\
19.0 \\
1\end{array}$ \\
\hline 6 & II & $\begin{array}{c}\text { B S } \\
\text { A-S } \\
\text { S }\end{array}$ & $\begin{array}{c}100 \\
24.2 \\
81\end{array}$ & $\begin{array}{r}386 \downarrow \\
23.0 \\
\times 65\end{array}$ & $\begin{array}{c}342 \\
25.5 \\
21\end{array}$ & $\begin{array}{c}292 \\
25.6 \\
51\end{array}$ & $\begin{array}{c}352 \\
24.6 \\
88\end{array}$ & $\begin{array}{c}352 \\
24.9 \\
64\end{array}$ & $\begin{array}{c}331 \\
23.8 \\
19\end{array}$ & $\begin{array}{r}205 \\
3\end{array}$ & $\dagger$ & \\
\hline 7 & II & $\begin{array}{c}\text { B S } \\
\text { A-S } \\
\text { S }\end{array}$ & $\begin{array}{c}106 \\
28.5 \\
96\end{array}$ & $\begin{array}{c}324 \downarrow \\
\times 32\end{array}$ & $\begin{array}{c}292 \\
24.5 \\
2.5\end{array}$ & $\begin{array}{c}338 \\
30.4 \\
41\end{array}$ & $\begin{array}{c}312 \\
31.3 \\
15\end{array}$ & 285 & $\begin{array}{c}266 \\
30.2 \\
30\end{array}$ & $\begin{array}{c}205 \\
29.1 \\
32\end{array}$ & $\begin{array}{c}174 \\
29.4 \\
40\end{array}$ & $\begin{array}{c}164 \\
30.2 \\
64\end{array}$ \\
\hline 8 & II & $\begin{array}{c}\text { B S } \\
\text { A-S } \\
\text { S }\end{array}$ & $\begin{array}{c}102 \\
27.6 \\
46\end{array}$ & $\begin{array}{l}330 \downarrow \\
29.3 \\
\times 10\end{array}$ & $\begin{array}{c}344 \\
32.5 \\
29\end{array}$ & $\begin{array}{c}334 \\
30.3 \\
20\end{array}$ & $\begin{array}{c}244 \\
25.4 \\
22\end{array}$ & $\begin{array}{c}202 \\
26.7 \\
28\end{array}$ & $\begin{array}{c}216 \\
30.2 \\
36\end{array}$ & $\begin{array}{c}184 \\
30.6 \\
53\end{array}$ & $\begin{array}{c}178 \\
32.5 \\
29\end{array}$ & $\begin{array}{c}150 \\
32.2 \\
29\end{array}$ \\
\hline 9 & II & $\begin{array}{c}\text { B S } \\
\text { A-S } \\
\text { S }\end{array}$ & $\begin{array}{l}112 \\
28.7 \\
253\end{array}$ & $\begin{array}{r}414 \\
\times 65\end{array}$ & $\begin{array}{c}386 \\
29.7 \\
21\end{array}$ & $\begin{array}{c}291 \\
27.1 \\
28\end{array}$ & $\begin{array}{c}284 \\
23.8 \\
25\end{array}$ & $\begin{array}{c}23.7 \\
2\end{array}$ & $\begin{array}{c}265 \dagger \\
26.7 \\
0\end{array}$ & & & \\
\hline 10 & II & $\begin{array}{c}B S \\
A-S \\
S\end{array}$ & $\begin{array}{l}107 \\
27.8 \\
252\end{array}$ & $\begin{array}{r}344 \\
\times 49\end{array}$ & $\begin{array}{r}292 \\
\times 26\end{array}$ & $\begin{array}{c}263 \\
31.9 \\
68\end{array}$ & $\begin{array}{l}249 \\
25.8 \\
124\end{array}$ & $\begin{array}{l}205 \\
25.5 \\
158\end{array}$ & $\begin{array}{l}166 \\
26.5 \\
167\end{array}$ & $\begin{array}{l}141 \\
28.2 \\
217\end{array}$ & $\begin{array}{c}277 \ddagger \\
35.2 \\
99\end{array}$ & \\
\hline 11 & II & $\begin{array}{c}B S \\
A-S \\
S\end{array}$ & $\begin{array}{c}110 \\
32.1 \\
45\end{array}$ & $\begin{array}{c}341 \\
40.6 \\
16\end{array}$ & $\begin{array}{c}282 \\
36.0 \\
30\end{array}$ & $\begin{array}{c}237 \\
26.8 \\
35\end{array}$ & $\begin{array}{c}277 \\
25.2 \\
21\end{array}$ & $\begin{array}{c}246 \\
25.8 \\
34\end{array}$ & $\begin{array}{c}278 \\
32.5 \\
38\end{array}$ & $\begin{array}{r}280 \\
41\end{array}$ & $\begin{array}{c}284 \\
32.6 \\
40\end{array}$ & \\
\hline 12 & II & $\begin{array}{c}\text { B S } \\
\text { A-S } \\
\text { S }\end{array}$ & $\begin{array}{l}104 \\
27.7\end{array}$ & $\begin{array}{l}365 \\
31.5 \\
\times\end{array}$ & \begin{tabular}{|c}
372 \\
34.7 \\
5
\end{tabular} & $\begin{array}{l}284 \\
29.8\end{array}$ & $\begin{array}{c}153 \\
27.5 \\
36\end{array}$ & & & $\begin{array}{c}191 \\
27.2 \\
37\end{array}$ & $\begin{array}{c}261 \\
27.8 \\
32\end{array}$ & $\begin{array}{r}219 \\
62\end{array}$ \\
\hline 13 & III & $\underset{\mathrm{S}}{\mathrm{B} S}$ & $\begin{array}{c}107 \\
30.2 \\
82\end{array}$ & $\begin{array}{l}310 \\
31.7 \\
\times 15\end{array}$ & \begin{tabular}{|c}
230 \\
31.6 \\
22
\end{tabular} & $\begin{array}{c}216 \\
30.2 \\
31\end{array}$ & $\begin{array}{c}146 \\
30.8 \\
43\end{array}$ & $\begin{array}{c}144 \\
30.5 \\
57\end{array}$ & $\begin{array}{c}131 \\
30.4 \\
81\end{array}$ & & & \\
\hline 19 & IV & $\begin{array}{c}\text { B S } \\
\text { A-S } \\
\text { S }\end{array}$ & $\begin{array}{c}109 \\
27.5 \\
70\end{array}$ & $\begin{array}{l}146 \\
27.8\end{array}$ & $\begin{array}{c}108 \\
27.2 \\
23\end{array}$ & $\begin{array}{c}112 \\
27.6 \\
54\end{array}$ & $\begin{array}{c}103 \\
27.6 \\
72\end{array}$ & & & & & \\
\hline
\end{tabular}

* BS blood sugar (mg.\%), A-S azorubin-S test (\%), S sodium santonate test.

$\downarrow$ insulin administration. $\times$ renal injury. $\quad \downarrow$ died of serious disease. $\downarrow$ died by accident.

b) $A-S$ test

Type I. The percentage of output in the 1 st or 2 nd week increased 


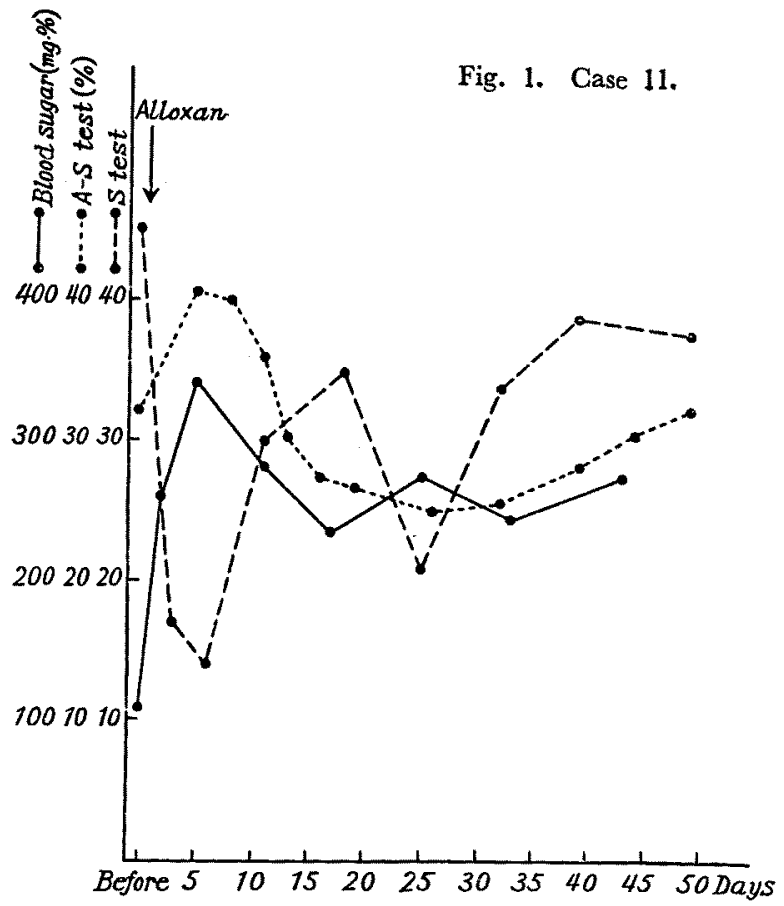

in all cases over the normal value by $2-16 \%$.

Type II. On the occurrence of diabetes reading of the percentage increased, as is shown in Table I and Fig. 1, except in Case 7, reaching the highest value (1-8.5\% higher than normal) in the 1st or 2nd week, then decreased till it came to the lowest value almost in the 4th week. Here, the readings of Cases 5, 6 and 12 were directly restored to normal, while those of Cases 8, 9, 10 and 11 decreased to lower than the normal value, then gradually increasing again to normal by the 7 th week. In other words, the lowest values of the former three were their respective normal values, while those the latter four arrived at were lower than normal. Case 7 alone, taking its own course, culminated in the 4th week and then decreased, still showing higher values than normal.

In the chronic diabetic stage Cases 5 and 10 showed a significant increase of reading when the diabetes was aggravated, but generally speaking, other cases, in spite of rather manifest diabetes persisting, presented most often normal values except for Cases 7 and 8 which still had readings higher than normal in their improving stage when glycosuria had disappeared. Further to say, Case 5 showed remarkably low reading, by far lower than normal, when the disease was serious. 
Type III. When diabetes was produced, in one case (Case 13, Table I) a slight and in 2 other cases a mild decrease were exhibited of their readings; they returned to normal in the 3 rd to 5 th week when the diabetes improved. In another case no change took place. The other one continued to increase mildly from the beginning of the disease till after recovery.

Type IV. In 2 cases the reading showed no change. In another it decreased mildly till the 2nd week, afterwards became normal. In the other one an increase in the reading of $8.5 \%$ was shown in the 1 st week, after the 2nd week a mild increase followed.

c) Effect of standard diet upon liver function

As experimental materials were employed 4 diabetic rabbits of Type II of 50 to 150 days after alloxan administration and 3 uninjected rabbits for control.

TABLE II

Influence of Standard Diet upon Liver Function

\begin{tabular}{|c|c|c|c|c|c|c|c|c|c|}
\hline \multirow{3}{*}{$\begin{array}{l}4 \\
0 \\
\dot{0} \\
\dot{0}\end{array}$} & \multirow{3}{*}{ 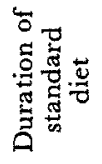 } & \multicolumn{3}{|c|}{$S$ test } & \multicolumn{3}{|c|}{ A-S test } & \multirow{2}{*}{\multicolumn{2}{|c|}{$\frac{\text { Blood sugar mg. } \%}{\text { Standard diet }}$}} \\
\hline & & \multirow{2}{*}{$\begin{array}{l}\text { before } \\
\text { alloxan }\end{array}$} & \multicolumn{2}{|c|}{ Standard diet } & \multirow{2}{*}{$\begin{array}{l}\text { before } \\
\text { alloxan }\end{array}$} & \multicolumn{2}{|c|}{ Standard diet } & & \\
\hline & & & before & after & & before & after & before & after \\
\hline \multirow{2}{*}{5} & 4 & \multirow{2}{*}{24} & \multirow{2}{*}{11} & 43 & \multirow{2}{*}{26.1} & \multirow{2}{*}{29.1} & 26.9 & \multirow{2}{*}{422} & 428 \\
\hline & 9 & & & 71 & & & 21.2 & & 329 \\
\hline \multirow{2}{*}{6} & 4 & \multirow{2}{*}{81} & \multirow{2}{*}{8} & 31 & \multirow{2}{*}{24.2} & \multirow{2}{*}{23.8} & 18.0 & \multirow{2}{*}{302} & 268 \\
\hline & 9 & & & 94 & & & & & 268 \\
\hline \multirow{2}{*}{$7 a^{*}$} & 5 & \multirow{2}{*}{96} & \multirow{2}{*}{22} & 56 & \multirow{2}{*}{28.5} & \multirow{2}{*}{30.0} & 26.5 & \multirow{2}{*}{268} & 205 \\
\hline & 15 & & & 83 & & & 26.5 & & 205 \\
\hline \multirow{2}{*}{$7 b^{*}$} & 3 & \multirow{2}{*}{96} & \multirow{2}{*}{64} & 64 & \multirow{2}{*}{28.5} & \multirow{2}{*}{28.4} & 28.0 & \multirow{2}{*}{174} & 93 \\
\hline & 10 & & & 94 & & & 24.1 & & 93 \\
\hline $11 a^{*}$ & 8 & 45 & 38 & 107 & 32.1 & 32.5 & 22.1 & 278 & 188 \\
\hline \multirow{2}{*}{$11 b^{*}$} & 4 & \multirow{2}{*}{45} & \multirow{2}{*}{41} & 56 & 321 & 325 & 24.6 & 290 & 181 \\
\hline & 11 & & & 108 & & & 23.4 & & 181 \\
\hline $22 \dagger$ & 10 & & 70 & 76 & & 23.5 & 23.7 & & \\
\hline $23 \dagger$ & 10 & & 44 & 39 & & 26.5 & 26.8 & & \\
\hline
\end{tabular}

* $a$ and $b$ signify the 1 st and 2 nd experiments respectively of the same animal. t control case. 
Effect of the standard diet on liver function was without any exceptions observed remarkably in diabetic cases, though not in control cases at all (Table II).

$\mathrm{S}$ test. Before putting them upon the standard diet their output had in all cases decreased, though in different degrees, but about the 4 th day of the diet it obviously increased except the mild Case $7 \mathrm{~b}$, and between the 8 th and 15th day the increase was so great as to exceed the normal value except for Case 7.

A-S test. The reading before the standard diet was begun was normal or increased to a mild degree. After the diet was given for 815 days it conspicuously decreased to show a value lower than normal in all cases.

\section{Summary AND Discussion}

In respect to the liver lesions in the early stage of alloxan diabetes there have been a number of experimental results published by various researchers.

In several kinds of animals hepatic injury is often observed after alloxan administration. A report ${ }^{3)}$ is made that in this case the severity is very different according to different species. As to the relation between hepatic injury and dosage of alloxan Bailey" emphasizes that the larger the dosage that has been administered, the greater the toxic effect in all species. On the other hand, Lukens" ${ }^{5}$ reports " the incidence and severity of hepatic involvement could not be related to the dosage of alloxan."

To turn our eyes on the reports on hepatic injury accompanying the diabetes in rabbits, Hard et al.6) observed no histological change after administering 50-100 mg. of alloxan per $\mathrm{kg}$. of body weight. Bailey et al.3) and Okamoto") observed slight degeneration with $200 \mathrm{mg}$. injected; Kendell et al. ${ }^{8)}$ reported fairly serious lesion caused by $125 \mathrm{mg}$. of alloxan per $\mathrm{kg}$. In my observation of alloxan diabetes dysfunction of liver was noticed in all cases regardless of the dosage of alloxan. It was characteristic especially in Type II. The disturbance of liver in Type II was detected by both $\mathrm{S}$ test and A-S test, though slightly by the latter, simultaneously with the appearance of diabetes. This injury reached its maximum in the 1st or 2nd week, then gradually grew improved and about in the 4 th week was at its minimum. In this stage A-S test proved the recovery of the excretory function of the liver to normal or inferred its hyperfunction, but $\mathrm{S}$ test showed the disturbance of detoxicating function was still somewhat serious.

On the other hand, in Type IV disturbance was discovered in all cases by $S$ test and in half of the cases by A-S test. It generally dis- 
appeared by the 4 th week. This disturbance in Type IV was caused by alloxan alone, as there was no diabetes induced.

In respect to liver disturbance Type II and Type IV are found to hold parallel course in decreasing or increasing, especially through $\mathbf{S}$ test. But the disturbance in the former type is much severer and in the 4th week is cleanly told by $S$ test to still persist, though by this time that in the latter has completely disappeared, and afterwards shows no great change. This comparison leads to conclude that the remarkable disturbance observed in Type II in the 1st or 2nd week had not been produced by alloxan alone, but with collaboration from diabetes and that the disturbance in the same type noticed after the 4th week was that caused by diabetes which was made exposed in consequence of disapppearance of alloxan influences.

As for other types, Type I is the extreme case of Type II, where the serious diabetes made the liver dysfunction severe enough to cause the death of the stricken animals. Type III is, as it was, the abortive Type II. In this type disturbance shown by $\mathrm{S}$ test ran an intermediate course of Type II and Type IV to recovery, not stopping in the 4th week as in Type II, because there was improvement in diabetes in the preceding 2nd or 3rd week, and spending more time in returning to normal than in Type IV.

As for the liver function in chronic diabetes, influences of alloxan were, as stated before, gone out by about the 4th week. Therefore, the dysfunction of liver observed after the 5th week, was, unless complicated, caused by diabetes.

On the histological examination of rabbits. Bailey et al.,3) Duff et al.9) and Okamoto ${ }^{7}$ recognized no abnormality of liver, and Lewis et al. ${ }^{10)}$ told of the same plasma protein changes (i.e. a marked increase in the B-globulin and decrease in albumin levels) in rabbits as in human diabetes.

According to the results of my observation on uncontroled alloxan diabetes, $\mathrm{S}$ test proved there almost always to be disturbance in all cases and there to be a certain relation between the severity of disturbance and that of diabetes. But in A-S test distrubance was detected only in half of the cases, the disturbance not always being related to the severity of diabetes.

As regards liver dysfunction of human diabetes Kaito ${ }^{11}$ found positive result in $70 \%$ of 45 cases (54\% of mild and $89 \%$ of serious cases) by $\mathrm{S}$ test and in $65 \%$ of 43 cases (there is no statistically significant difference between the mild and serious cases) by A-S test. Koga ${ }^{12}$ reports positive $\mathrm{S}$ test in $45.5 \%$ of 22 cases, Nakagawa et al. ${ }^{13)}$ positive A-S test in 2 cases out of 4 . 
It gives us a deep interest to know that my experiment of alloxan diabetes has reached substantially the same result as of human diabetes.

Now for the effect of "standard diet" Kaito" ${ }^{11)}$ examined by $S$ test the influences of dietary treatment on liver function of human diaabetics and observed improvement in 6 out of 13 mild and 6 out of 10 serious cases. I made researches as to the effect of standard diet upon liver function in alloxan diabetes by both S test and A-S test and not only found improvement in all cases, but obtained such results as to suggest hyperfunction of liver in most cases. This effect gradually strengthened till about 8 days from the beginning of the treatment, but thereafter seemed not to make any remarkable changes.

When the standard diet was followed by free diet, the effect was gone off almost in a week and the liver function resumed the level before the standard diet.

\section{Conclusions}

1. In the early stage of alloxan diabetes there was remarkable dysfunction of liver. observed which was caused by diabetes and, further, strongly influenced by alloxan, influence of the latter acutely passing away.

2. Dysfunction of the liver in chronic alloxan diabetes was detected in all cases by santonin test and in half of the cases by azorubin $\mathrm{S}$ test.

3. Liver function in alloxan diabetes was remarkably improved by the treatment of standard diet.

\section{References}

1) Takasugi, T. and Miyamoto, E., Nippon Naika Gakkai Zasshi, 1937, 25, 765.

2) Fujita, A. and Iwatake, O., Biochem. Zschr., 1931, 242, 43.

3) Bailey, O. T., Bailey C. C., and Hagen, W. H., Amer. J. Med. Sci., 1944, 208, 450.

4) Bailey, C. C., The Treatment of Diabetes Mellitus, 8. edit., Lea \& Febiger, Philadelphia 1947, 178.

5) Lukens, F.D.W., Physiol. Rev., 1948, 28, 304.

6) Hard, W.L. and Carr, C.J., Proc. Soc. Exper. Biol. \& Med., 1944, 55, 214. 1951.

7) Okamoto, K., Experimental Pathology of Diabetes Mellitus, Tokyo \& Kyoto (jap.),

8) Kenndel, F.E., Meyer, W., Lewis, L. and Victor, T., Proc. Soc. Exper. Biol. \& Med., 1945, 60, 190.

9) Duff, G. L., McMillan G.C., and Wilson, D.C., Proc. Soc. Exper. Biol. \& Med., 1947, 64, 251.

10) Lewis, L.A., Moses, J. and Schneider, R.W., Amer. J. Med. Sci., 1947, 213, 214.

11) Kaito, I., Tohoku J. Exper. Med., 1949, 51, 247.

12) Koga, H., Jikken Shokaki Byogaku, 1940, $15,73$.

13) Nakagawa, H. and Mitani, Y., Hokkaido Igaku Zasshi, 1933, 11, 2108. 